NOTAS

CRÍTICAS

\section{En busca de}

textualidades críticas.

Ortodoxia memorial

y campo literario

Violeta Ros Ferrer

Universitat de València

DOI: 10.1344/452f.2021.25.15

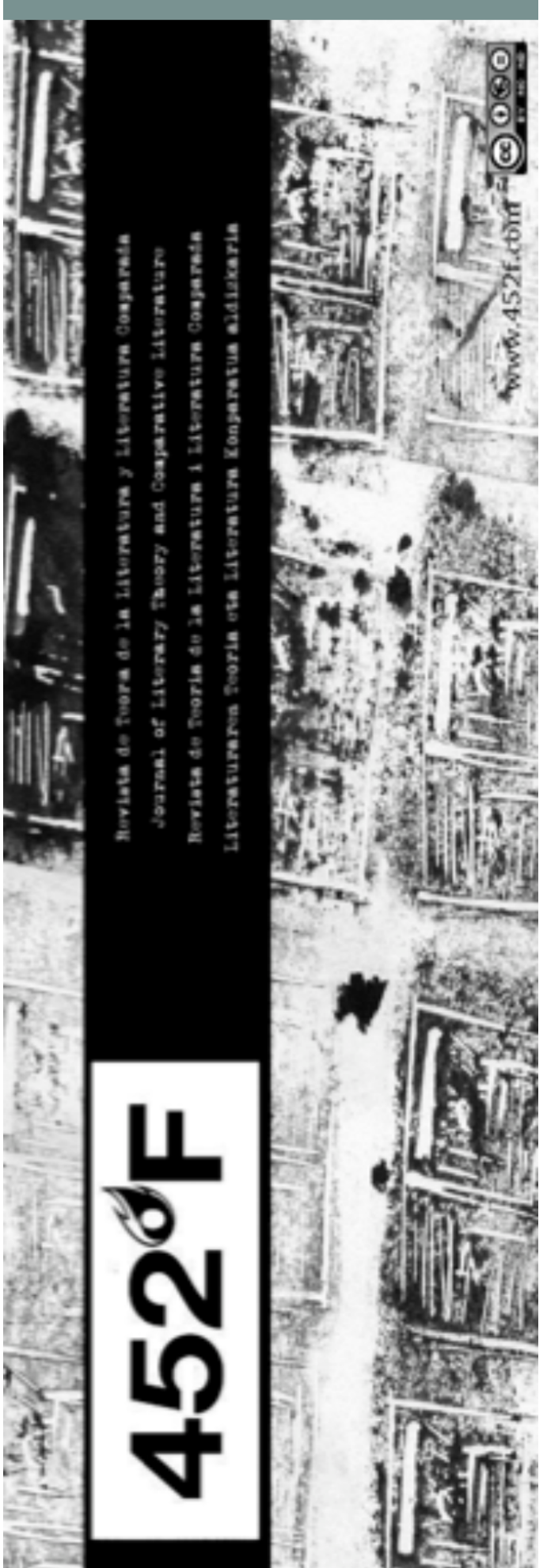

fácil observar hasta qué punto existe una dinámica por la que los discursos relativos a la memoria de la represión parecen convocar, hoy, voces y gestos estéticos que no emanan de las propias lógicas del proceso memorial -es decir, de los tiempos, de las formas, y de los discursos que van apareciendo en relación con las demandas de memoria, justicia y reparación - o de una escucha verdaderamente atenta a las dinámicas propias de este proceso, sino que, en un gesto de extractivismo intelectual, acaban fagocitando los relatos sobre el pasado y los sustituyen por un discurso impostado - sentimental e ideológicamente-, pero rentable, en términos de capital simbólico y cultural.

Esta idea es fuerte: voy a intentar explicarla y matizarla.

Al pensar, con Ana Luego, sobre el proceso de gentrificación del espacio de la memoria en el contexto cultural español, la metáfora revela una doble dimensión. Por un lado —y esto está en la reflexión de Luengo-, aparece esta primera idea del devenir neoliberal de los relatos culturales de la memoria como el resultado de la conquista a toda costa de un mercado cultural «supuestamente político» y de «un público potencial sensible», a través del "puro ornamento» (Luengo, 2017: 28). Pienso, por ejemplo, en el éxito de películas como La trinchera infinita (2019) o de novelas como las que componen los Episodios de una guerra interminable de la escritora Almudena Grandes, sobre los que volveré más abajo. Por otro lado, y si nos dejamos llevar por el significado literal del concepto desde la perspectiva sociodemográfica, la metáfora de la gentrificación del espacio de la memoria apunta directamente hacia la expulsión de los procesos de memoria precisamente del sector de la población al que esta memoria le es propia - un sector que fue, sobre todo, popular y que no suele producir discurso público-, y hacia la ocupación de los espacios de visibilidad de esta memoria por parte de una élite cultural —intelectual, académica o literaria-, que es la que sí produce discurso. La memoria de la represión se convierte, así, en mercancía en el espacio académico o cultural. Y por extensión, también lo hacen los relatos de la memoria que circulan mayoritariamente por nuestro campo cultural contemporáneo, fundamentalmente en forma de novelas o películas de ficción.

Si pensamos exclusivamente desde la producción literaria (pensemos, por ejemplo, en el amplio y variado 
NOTAS

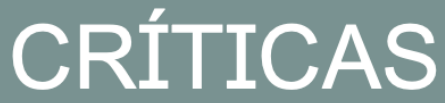

En busca de

textualidades críticas.

Ortodoxia memorial

y campo literario

Violeta Ros Ferrer Universitat de València DOI: 10.1344/452f.2021.25.15

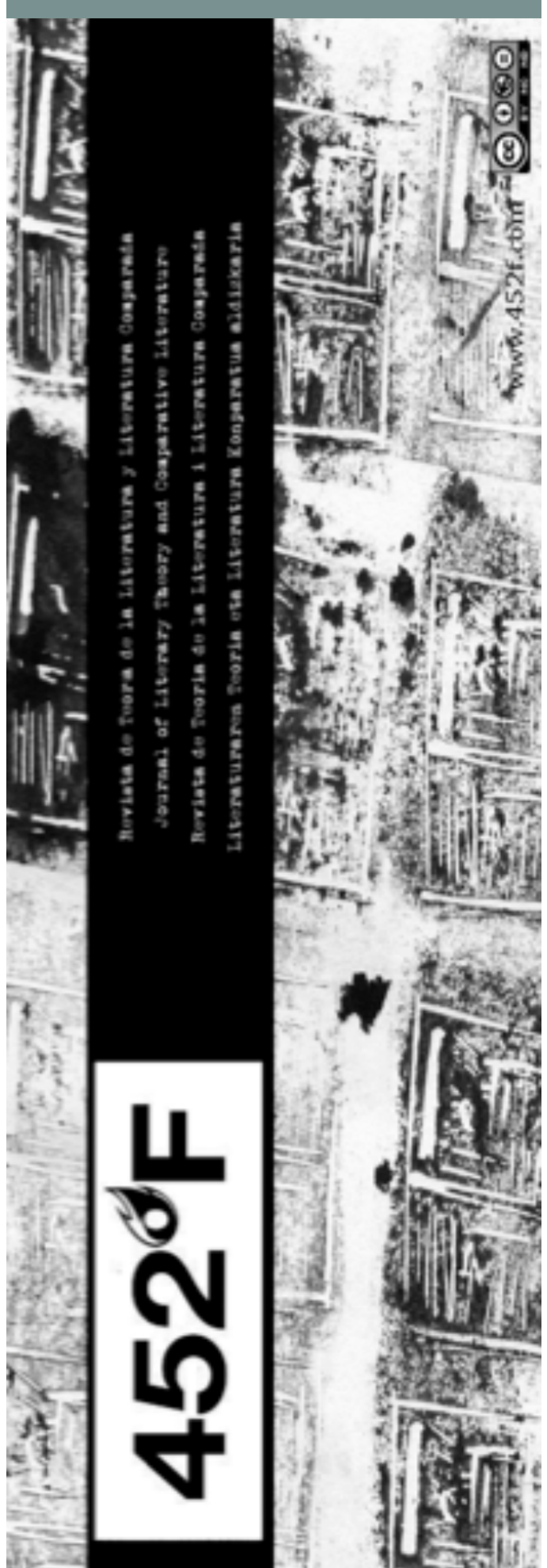

corpus de novelas publicadas sobre la Guerra Civil y la Transición a partir del llamado boom de la memoria), es fácil constatar hasta qué punto la mayoría de estos textos tienden a compartir unos códigos de género - la ficción o la autoficción-y una posición ética e ideológica con respecto a la lectura de ese pasado - generalmente la indagación en historias protagonizadas por las víctimas o por los vencidos-. Los ejemplos son inagotables: no hay más que echar un vistazo a la bibliografía específica de las últimas dos décadas. El auge de la llamada novela de la memoria es, a priori, una buena señal: un síntoma de salud democrática. Sin embargo, como ha explicado Ulrich Winter (2019), la sobreproducción de novelas y películas de estas características también es síntoma de que la cultura, en España, ha funcionado en las últimas dos décadas como un espacio de jurisdicción suplementaria: es decir, que en el campo cultural se han ajustado las cuentas pendientes con el pasado que, desde lo judicial, nunca fueron saldadas. Y como espacio de jurisdicción suplementaria, los códigos y los gestos compartidos por las novelas que siguen apareciendo sobre la represión vinculada a la Guerra Civil, el franquismo y la Transición, deben ser observadas, leídas e interpretadas con especial atención, porque no dejan de dar cuenta del contexto de impunidad de los crímenes cometidos por la dictadura en España y de los efectos a largo plazo que este contexto de impunidad conlleva en relación con las dificultades a la hora de construir una memoria democrática que esté a la altura de otros contextos de memoria (como el argentino o el alemán, por poner ejemplos concretos).

\section{Campo literario y ortodoxia memorial}

En relación con los relatos de la memoria, ocurre en el campo literario español que, a fuerza de repetición de los mismos gestos éticos y estéticos parece que, más de veinte años después de que se iniciara el auge de la llamada novela de la memoria, empiezan a agotarse las propuestas estéticas y narrativas. Salvo en excepcionales ocasiones - y aquí pienso, por ejemplo, en las novelas de Marta Sanz o de Edurne Portela, en las que, por cierto, el trabajo sobre el lenguaje como materia cobra un protagonismo inusual en la construcción de relatos sobre la memoria de la violencia política-, suele ocurrir que los relatos sobre el pasado se vacían de sentido y se convierten en un mero paisaje en el que ambientar tramas inocuas que 
NOTAS

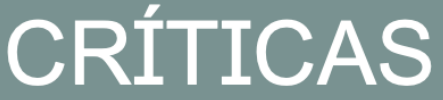

\section{En busca de}

textualidades críticas.

Ortodoxia memorial

y campo literario

Violeta Ros Ferrer Universitat de València DOI: 10.1344/452f.2021.25.15

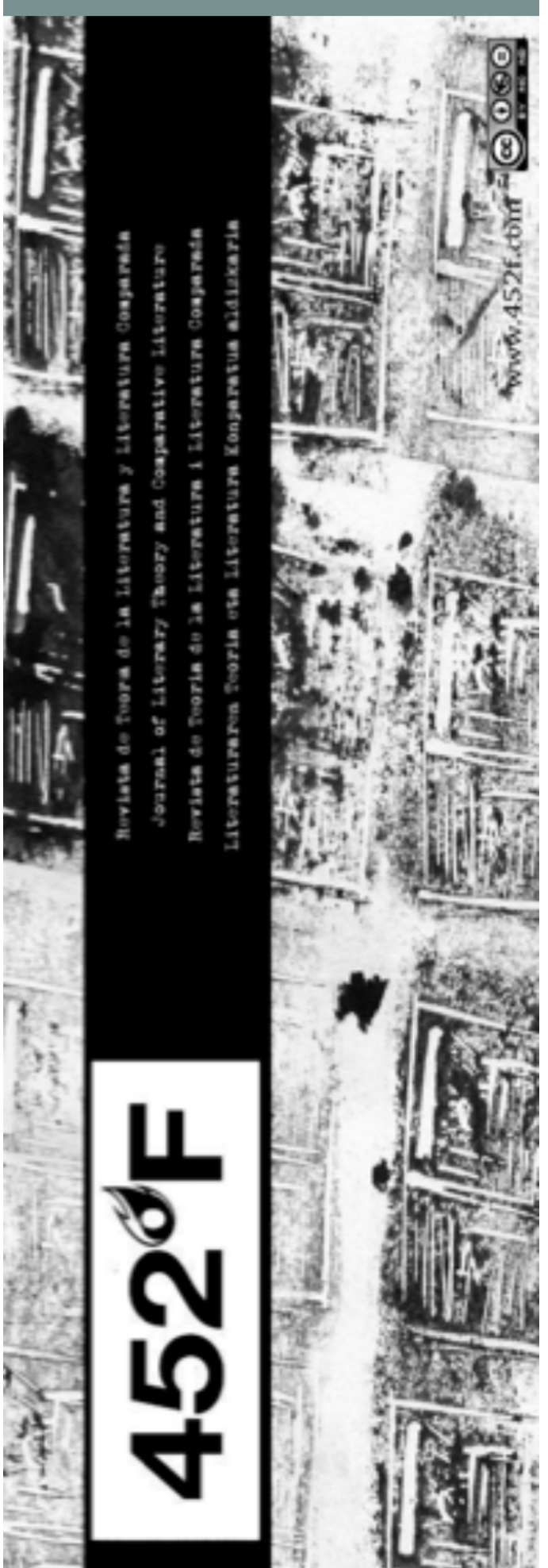

no movilizan a los lectores más allá de lo meramente sentimental, sumiéndolos en la inercia del consumo de un género literario como cualquier otro $y$, en consecuencia, generando también la deslibidinización de cualquier análisis crítico al respecto. Esto ocurre de una forma muy visible, por ejemplo, en las novelas que conforman los Episodios de una guerra interminable a los que me refería más arriba. Sin dejar de reconocer la capacidad seductora de Almudena Grandes como narradora e incluso la posición militante en relación con la memoria histórica de la que parte su serie de novelas sobre la Guerra Civil y el franquismo, como artefactos narrativos estas novelas dejan caer todo el peso del ejercicio memorial en la construcción de tramas más o menos espectaculares y en personajes arquetípicos que, en realidad, son propios de los códigos del best seller. Lo problemático de este tipo de novelas, a mi juicio, está en la recepción: y es que, a través de estas tramas y personajes, generan un relato tan simplificado del contexto de la represión y tan mediado por la movilización afectiva del lector, que acaban por reproducir un relato maniqueo del pasado - los rojos, los azules; los malos, los buenos - que perpetúa, aunque desde una posición claramente comprometida con los valores progresistas, el vaciamiento ideológico de los relatos sobre la violencia y la represión ante el gran público. Hay más ejemplos en los que este vaciamiento se produce, aunque mediante operaciones textuales e intelectuales de muy distinta naturaleza. Pienso, por ejemplo, en las novelas de Javier Cercas -Soldados de Salamina (2001), Anatomía de un instante (2009), Las leyes de la frontera (2012), El impostor (2014)_, y podríamos encontrar más ejemplos entre la producción narrativa de los autores más consolidados en el campo de la novela actual.

Para tratar de revertir esta especie de callejón sin salida de las representaciones de la memoria, podríamos empezar por asumir que, en los últimos años, hemos ido construyendo, entre todos, una cierta ortodoxia memorial ${ }^{1}$ que, tanto desde cierto pensamiento académico como desde las propias representaciones culturales - dos circuitos que, por otra parte, se retroalimentan de forma cada vez más que evidente-, han marcado las coordenadas ideológicas y afectivas desde las que pensar el pasado reciente. Esta ortodoxia memorial surgida de un contexto claramente deficiente -al menos hasta la fecha - con respecto la construcción desde el Estado de una memoria democrática que verdaderamente lo 
NOTAS

CRÍTICAS

\section{En busca de}

textualidades críticas.

Ortodoxia memorial

y campo literario

Violeta Ros Ferrer

Universitat de València

DOI: 10.1344/452f.2021.25.15

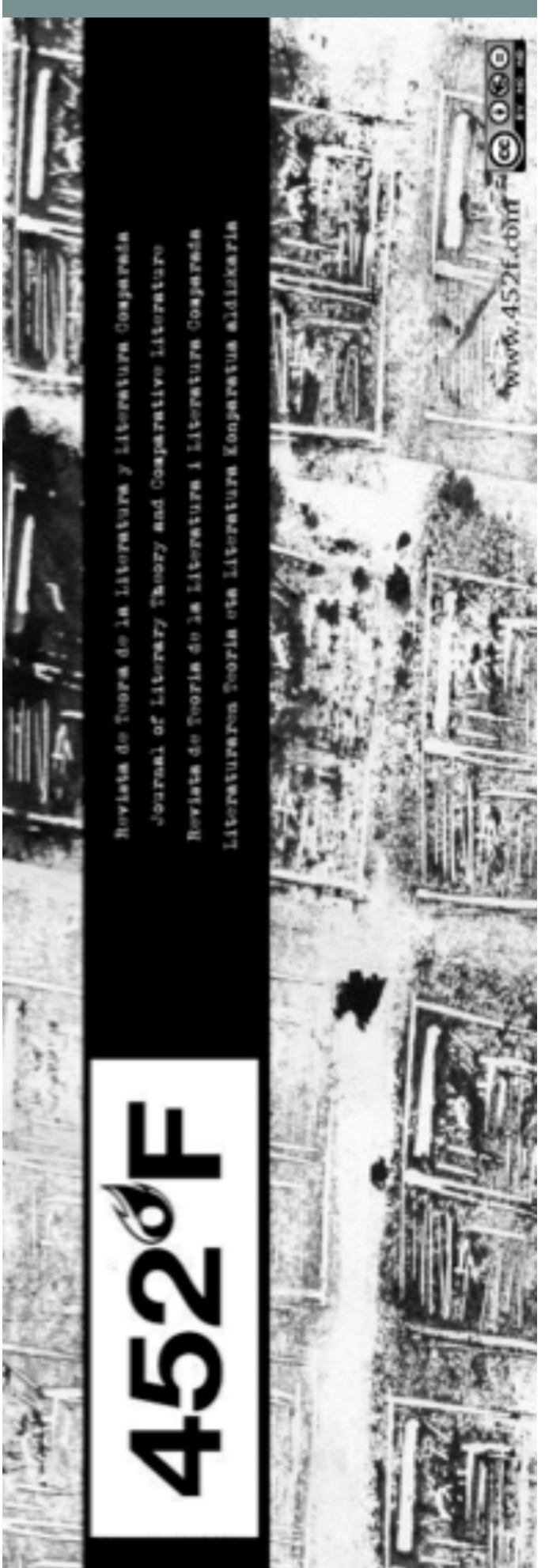

íntima. La pregunta, entonces, es: ¿de qué manera los relatos culturales pueden contribuir a la consolidación de estos mapas de la memoria en lugar de apuntalar eso que Germán Labrador llama decoro democrático?

\section{Memoria familiar y materia narrativa: una} propuesta de indagación en el pasado

Más de dos décadas después de haberse iniciado el proceso de construcción de una memoria pública de la represión en el Estado español, hemos aprendido, por fin, que, si queremos abordar los estudios de la memoria y sus representaciones culturales desde una perspectiva crítica y de una forma sostenible y no gentrificadora del territorio memorial, no debemos perder de vista la doble dimensión de todo proceso de memoria: la dimensión íntima (privada) y la dimensión pública (social). Aunque constituyen dos escenarios diferentes en los que el pasado se hace presente, entre estas dos dimensiones acaba existiendo un encaje más o menos precario que suele requerir de una peculiar negociación. La memoria de los procesos de violencia política es un escenario en el que esa negociación entre lo público y lo privado se produce de manera especialmente visible. Los relatos culturales, en sus múltiples formas y soportes, tienen la capacidad de ofrecernos una puerta de entrada al engranaje, a la conexión, que se establece entre esas dos dimensiones de la memoria y también una alternativa a la producción de relatos culturales afines a esa ortodoxia memorial.

En tanto que espacio íntimo y en tanto que universo autónomo y constelado en torno a una serie de códigos, afectos y lealtades específicas, la memoria familiar funciona como la mínima expresión de lo que Maurice Halbwachs llamó la «comunidad afectiva» (Halbwachs, 2004: 33). En este sentido, podemos pensar la memoria familiar — con los mecanismos y procesos que le son propios - como una réplica a pequeña escala de las lógicas memoriales —y también de las tensiones - que se dan en la esfera pública. La memoria familiar constituye, en definitiva, un escenario en el que los procesos políticos se encarnan en las historias de vida que circulan de una generación a otra en el entorno familiar, transmitiéndose y transformándose, con el tiempo, en diferentes versiones de un mismo relato. 
NOTAS

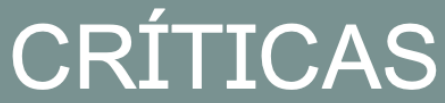

En busca de

textualidades críticas.

Ortodoxia memorial

y campo literario

Violeta Ros Ferrer

Universitat de València

DOI: 10.1344/452f.2021.25.15

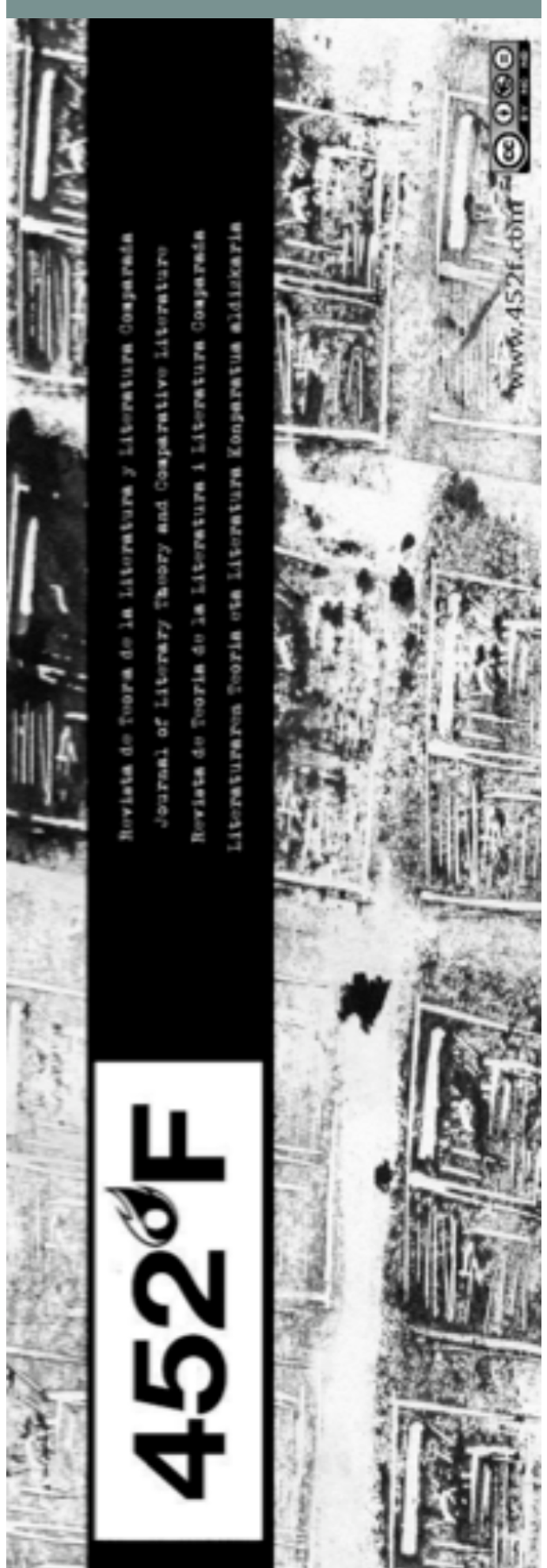

En todas las familias hay relatos y hay silencios. Los relatos familiares, en general, suelen ser más fáciles de desentrañar que sus silencios: porque, aunque sean contradictorios, inexactos o estén sesgados, contienen un material susceptible de ser descifrado. Los silencios familiares, por el contrario, son más densos y resultan más difíciles de desentrañar. Desde un paradigma narrativo que nombraré «etnografías domésticas del franquismo» -adaptando un término propuesto por Michael Renov para el análisis del discurso fílmico (2004)_- es posible analizar un conjunto de materiales culturales que suponen un modelo narrativo muy sugerente a la hora de explorar, desde los códigos híbridos de la no ficción, en los puntos ciegos del marco memorial contemporáneo a través de la indagación en esos silencios de la memoria familiar.

En su trabajo The Subject of Documentary, Renov constataba cómo en un llamativo número de películas documentales aparecidas en Estados Unidos en la década de los noventa se daba un solapamiento explícito de las preocupaciones personales e individuales con aquellas cuestiones que él llama de «urgencia política». Este solapamiento, según el análisis de Renov, cobraba forma narrativa a través de una peculiar combinación entre las estrategias de autoindagación subjetiva (self-interrogation) con una preocupación etnográfica por documentar las vidas de los otros más cercanos —del "otro doméstico», dirá Renov-, en un contexto, dice textualmente, "de gran curiosidad genealógica» (2004: 218). De este modo, lo doméstico y los diferentes componentes que constituyen el universo familiar aparecen como un escenario disponible al trabajo de campo; un trabajo susceptible de ser narrable e interpretable desde una perspectiva que enlaza la indagación en la identidad propia con la indagación en las historias de vida de los miembros de la familia o cercanos a ella. En este contexto de curiosidad genealógica, la relación especular con los vínculos familiares es una cuestión de la que el autor de la etnografía doméstica no puede ni quiere escapar y por ello, a través de su discurso, trata de reacomodar sus propias coordenadas éticas y subjetivas a las coordenadas marcadas por el relato familiar.

Como modelo narrativo, este tipo de indagaciones en las memorias familiares vinculadas a los procesos de violencia política parten de la voluntad compartida de rescatar historias perdidas, de desvelar los silencios, las verdades a medias o, directamente, los secretos 
NOTAS

CRÍTICAS

\section{En busca de}

textualidades críticas.

Ortodoxia memorial

y campo literario

Violeta Ros Ferrer

Universitat de València

DOI: 10.1344/452f.2021.25.15

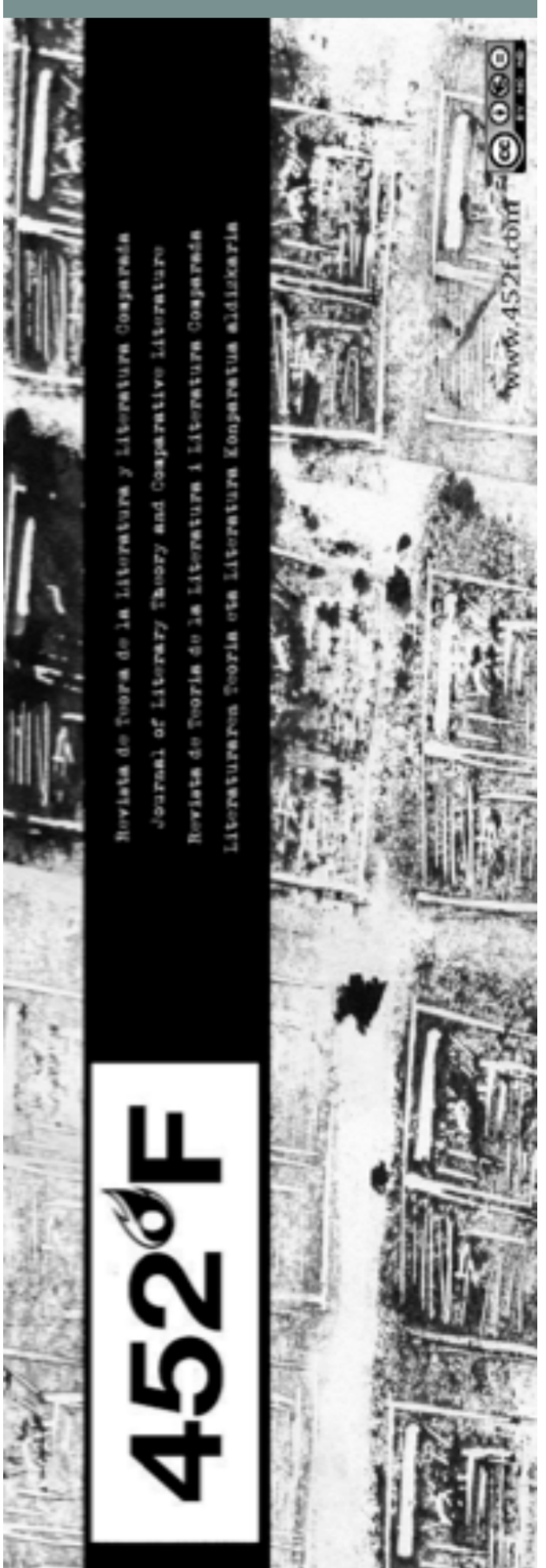

-ya sean estos intencionales o involuntarios - y completar o cotejar, con el trabajo de investigación histórica o trabajo documental, los marcos de sentido propios de la memoria familiar con los marcos sociales de la memoria, es decir: con la memoria colectiva. Esta premisa de indagación en el pasado implica dos gestos narrativos que se dan de forma simultánea. Por un lado, el sujeto de la investigación - generalmente el nieto - trata de construir una genealogía familiar que le proporcione unas coordenadas sociológicas que le permitan ubicarse subjetivamente en relación con esos procesos de violencia colectiva -qué papel jugaron sus antepasados en relación con la represión, cuál fue su actitud después, cuál es su actitud ahora, etc. Por otro lado, precisamente a través del trabajo de indagación en los orígenes del universo familiar propio $\mathrm{y}$, en no pocas ocasiones, de haber encontrado historias truculentas dentro de ese universo, quien indaga trata de separase de ciertos parentescos en relación con esa violencia, de desvincularse de la herencia recibida si esta no encaja en los parámetros éticos del autor de la investigación o de vincularse a ellos desde otro lugar, en el caso contrario. Es por eso que las cuestiones del legado y la filiación aparecen con fuerza en este tipo de ejercicios.

En las etnografías domésticas del franquismo ocurre de vez en cuando que la exploración en el pasado implica el desvelamiento de historias poco convenientes; historias que, en ocasiones van en contra de los intereses o la imagen proyectada de esa comunidad afectiva familiar en concreto y que desafían los marcos de esa ortodoxia memorial. En los últimos años, en el campo de la novela española actual han ido apareciendo una serie de narraciones que parecen haber dado un paso más allá en esta dirección. Con posicionamientos autoriales más o menos radicales, con intenciones narrativas diversas y con estéticas literarias dispares y variadas, narraciones como Lo que a nadie le importa (Del Molino, 2014), El monarca de las sombras (Cercas, 2017), Honrarás a tu padre y a tu madre (Fallarás, 2018) o Dicen (Arins, 2019) proponen el ejercicio de explorar el pasado familiar, poniéndolo en tensión con los marcos de comprensión del pasado colectivo y proponiendo un paradigma narrativo que disuelve los límites entre lo testimonial, lo etnográfico y lo ficcional. Me interesa explorar el eco de esta producción literaria, minoritaria dentro del grueso de la producción literaria memorial, pero con un gran potencial crítico que va, además, más allá de lo meramente literario. 


\section{CRÍTICAS}

\section{En busca de}

textualidades críticas.

Ortodoxia memorial

y campo literario

Violeta Ros Ferrer

Universitat de València

DOI: $10.1344 / 452 f .2021 .25 .15$

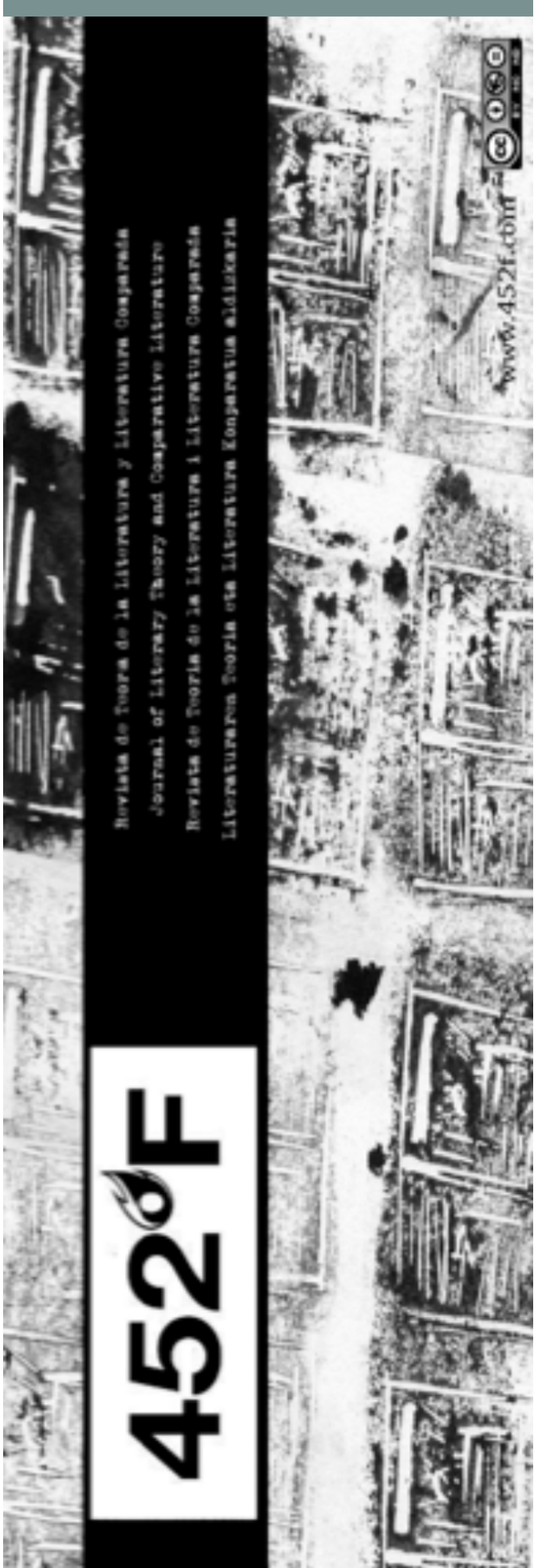

4. Otra vuelta de tuerca: la cuestión de los perpetradores

Este tipo de ejercicios implican, además, otra vuelta de tuerca en la forma de abordar narrativamente la memoria de la represión, ya que presentan la siguiente pregunta: ¿qué pasa cuando los relatos familiares contienen un tipo de información en relación con el pasado que encaja difícilmente con los marcos de comprensión desde los que ese pasado se lee desde el presente? Lo que tienen en común los textos que he mencionado más arriba es que el trabajo de la etnografía doméstica en relación con el franquismo está motivado principalmente por la indagación en un "otro doméstico» —un abuelo, un tío— de difícil encaje en los relatos decorosos de los que nos hablaba Germán Labrador, puesto que hablan de familiares cuyos relatos de vida están vinculados, de distintas maneras, con el ejercicio de la represión, es decir, con la perpetración de la violencia política durante la Guerra Civil y el franquismo, algo en lo que muy pocos relatos culturales se han adentrado desde el contexto español hasta la fecha.

Los estudios sobre la cuestión de la perpetración - lo que en el mundo anglosajón se conoce como perpetrator studies - constituyen uno de los últimos giros en los estudios globales de la violencia política, su memoria y sus representaciones. Esta propuesta consiste en desplazar el foco de la reflexión desde la centralidad de la figura de la víctima de la violencia política hacia una categoría mucho menos transparente $y$, por lo tanto, más difícilmente asible e identificable como lugar de análisis: la categoría del perpetrador. Más allá de su especificidad como significante dentro del léxico jurídico (un perpetrador es quien perpetra un crimen), esta categoría presenta, si la tomamos en un sentido lato, un gran potencial analítico. Desde esta plasticidad, el perpetrador deviene la contrafigura de la víctima: una contrafigura, en principio, abstracta en términos teóricos, pero que va adquiriendo significados concretos y específicos en función del contexto histórico y social del que forma parte. El franquismo y los crímenes cometidos en nombre del Estado entre 1939 y 1978 es uno de estos contextos.

Precisamente por su carácter opaco y, en ciertos contextos, de límites poco definidos, el propio concepto 
NOTAS

CRÍTICAS

\section{En busca de}

textualidades críticas.

Ortodoxia memorial

y campo literario

Violeta Ros Ferrer

Universitat de València

DOI: 10.1344/452f.2021.25.15

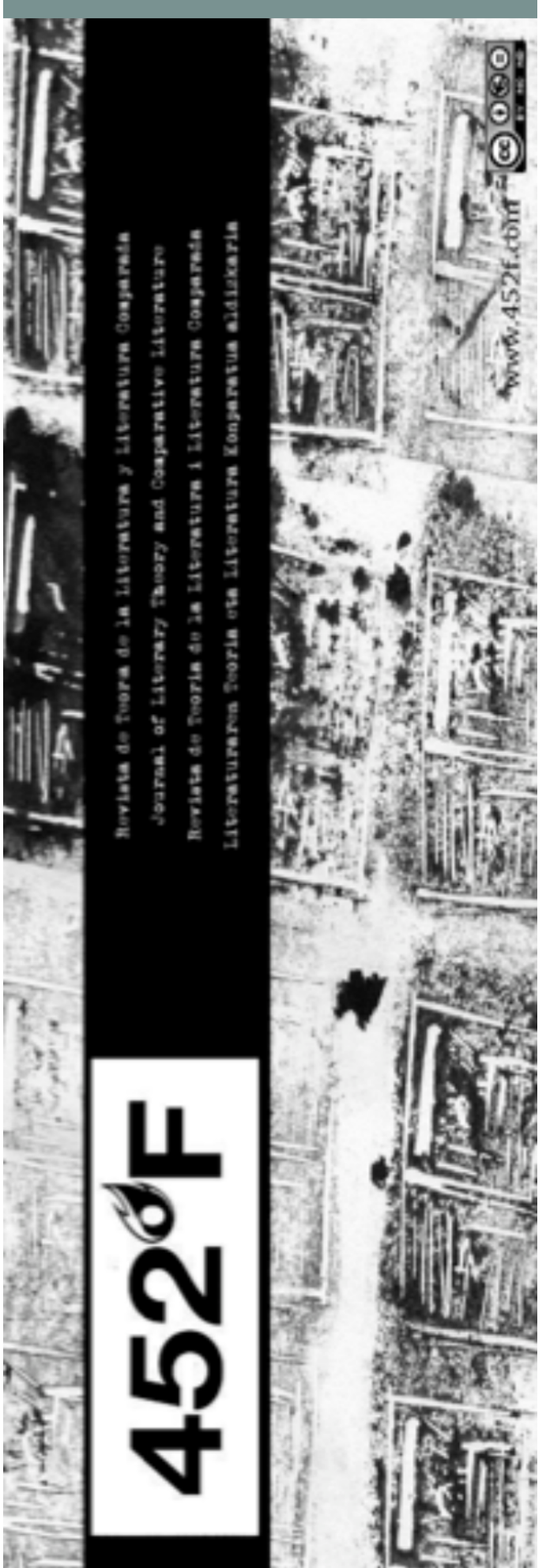

invita a pensar más allá de la figura individual del victimario y el verdugo: es decir, más allá del agente individual que perpetra la violencia. El giro de los perpetradores en los estudios de la memoria apunta, en realidad, hacia entramados sociales de gran alcance y duración en el tiempo y nos permite señalar sus efectos políticos y simbólicos en el presente a través de la reconstrucción de ciertos relatos sociales, como en el caso de las etnografías domésticas. La dificultad que presenta el análisis crítico de los relatos y las imágenes que giran en torno a estas contrafiguras de la violencia política en el contexto español alumbra un campo de investigación sugerente, altamente sensible, todavía poco explorado y difícilmente gentrificable en el territorio de la memoria. Un campo que nos permite incomodar esa ortodoxia memorial y que nos abre una puerta para seguir buscando nuevas formas desde las que interrogar al pasado sin quedarnos pedaleando en el vacío.

En un sugerente ensayo titulado Mi abuelo no era nazi. El nacionalismo y el Holocausto en la memoria familiar, los sociólogos Harald Welzer, Sabine Moller y Karoline Tschuggnall (2012) reflexionan en torno a la capacidad — y también en torno a la incapacidad— de las terceras generaciones (los nietos) a la hora de hacer algo productivo —no en términos gentrificadores, sino en términos de producción social de memoria- con las experiencias y las memorias de quienes fueron contemporáneos al genocidio nazi. A través de la investigación sobre la circulación familiar de los relatos de participación y colaboración con el nazismo en Alemania, los autores de este ensayo observan que, aunque la mayoría de los abuelos entrevistados participaron con el régimen de algún modo, sus nietos tendían a reformular sus relatos hasta el punto de transformar anécdotas de colaboración con el nazismo en historias de opositores al régimen. "Los nazis siempre son los otros», parece acabar diciendo esta recopilación de relatos de nietos: unos "otros» abstractos que nunca identificamos como nuestros seres queridos, como nuestros «otros domésticos».

Lo interesante de este ensayo, pionero en el trabajo de análisis global de la transmisión intergeneracional de la memoria traumática, es que pone en cuestión el verdadero alcance de los discursos políticamente correctos del progresismo bienpensante - de esa ortodoxia memorial- y pone de manifiesto que existe una distancia entre lo que dicen quienes tuvieron una experiencia directa del genocidio en Alemania y lo que 
NOTAS

\section{CRÍTICAS}

\section{En busca de}

textualidades críticas.

Ortodoxia memorial

y campo literario

Violeta Ros Ferrer Universitat de València DOI: 10.1344/452f.2021.25.15

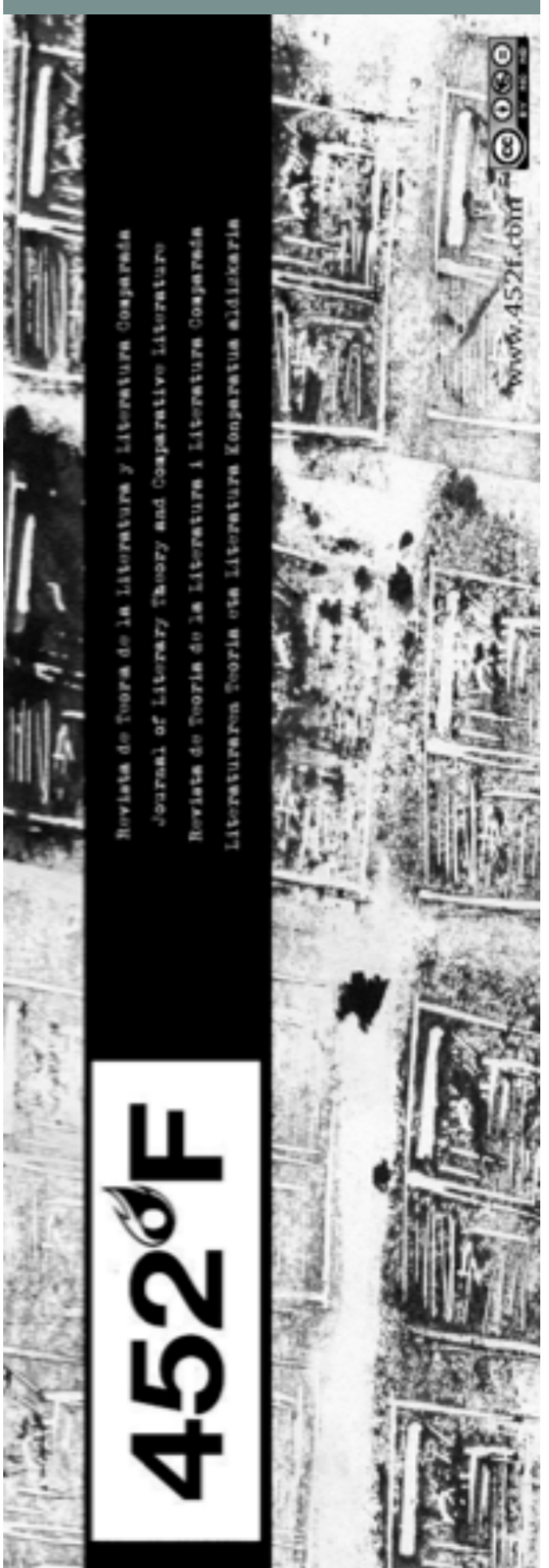

escuchan los hijos y los nietos en las narraciones de sus predecesores. Años después, en 2018, la periodista franco-alemana Géraldine Schwarz se hacía con el premio al mejor libro europeo con un ensayo titulado Los amnésicos. Historia de una familia europea, en el que, a través de la investigación en las actitudes hacia el régimen nazi dentro de su propia familia, desenmascaraba la generalización de las actitudes de colaboracionismo con el nazismo generalizadas entre buena parte de la población francesa y alemana de la época.

Este ejercicio de escucha distanciada de los relatos sobre el colaboracionismo en el contexto del nazismo nos dice, en realidad, algo importante: que la memoria familiar, como la memoria social, implica un proceso de construcción guiado por las necesidades del presente. $Y$ esto nos habla de un legado transgeneracional que puede ser aplicado, en realidad, a cualquier otro contexto de memoria. También al español. Aparece aquí el gesto de explorar ese legado transgeneracional como un gesto ético de gran potencial, en el que el recurso a la imaginación narrativa juega —o podría jugar - un papel de enorme importancia.

\section{En busca de textualidades críticas}

Es cierto que el nuevo marco global de comprensión de la memoria inaugurado en España en torno al año 2000 vino acompañado por un nuevo lenguaje con el que nombrar ese pasado; un lenguaje que procedía del ámbito del derecho penal internacional y que estaba vinculado a los procesos globales de justicia transicional. La repercusión de estos procesos en el avance de la construcción de un paradigma global de la memoria tuvo que ver fundamentalmente con la vernacularización o descarga legal (Ferrándiz, 2010) de algunas de las categorías surgidas de estos procesos (categorías jurídicas como genocidio, desaparecido, perpetrador), es decir, de su progresiva adaptación en distintos contextos locales. Ese marco global de memoria generó, a su vez, propuestas estéticas de indagación en el pasado que son, en su esquema más básico, compartidas por las prácticas culturales propias de los distintos contextos de memoria.

Sin duda, el desplazamiento del foco de atención desde el conflicto - Golpe de Estado de 1936, Guerra Civil y Dictadura- hacia el postconflicto 
NOTAS

CRÍTICAS

\section{En busca de}

textualidades críticas.

Ortodoxia memorial

y campo literario

Violeta Ros Ferrer

Universitat de València

DOI: 10.1344/452f.2021.25.15

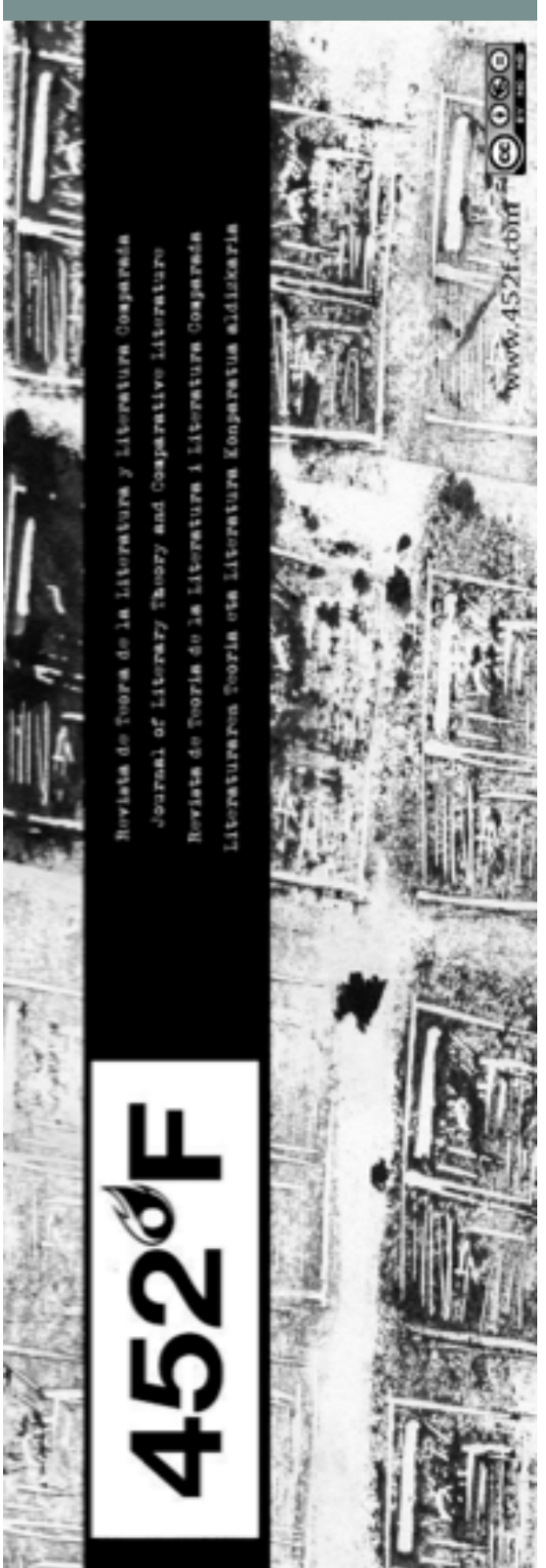

tardofranquismo y Transición- ocurrido en los últimos años en el caso español, ha permitido conectar los procesos de memoria histórica en España con las demandas de justicia transicional dentro de este marco transnacional de memoria. Lo deseable sería que esta conexión se estableciera también entre las distintas estéticas y textualidades que se muestran capaces de subvertir esa tendencia a la ortodoxia memorial en la que caen gran parte de los relatos culturales que consumimos dentro de esta lógica mercantil de la memoria. Sin embargo -y aquí la frustración crítica que he tratado de exponer en estas páginas - la indagación en los relatos de la memoria de la represión requiere de un ejercicio narrativo radical en relación con el pasado; de un deseo de contar no mediado por ningún decoro, que no es compatible con las lógicas gentrificadoras de la memoria a las que aludía al inicio de esta reflexión.

A mi juicio, es por esto que, en el campo literario español, empieza a producirse un vacío, una ausencia generalizada de propuestas que estén a la altura del potencial de este gesto que sí que está operando en lo social pero que no se acaba manifestar en los relatos culturales. Urgen, por tanto, textualidades críticas que permitan al lector explorar el límite entre lo documental y la ficción, y experimentar, a través de la lectura, la tensión dialéctica entre la representación y el poder narrativo inherente a la propia realidad social. La indagación en lo doméstico, en los parentescos incómodos, en los relatos y los silencios del universo familiar — de la memoria privada de la represiónconstituyen un patrón de investigación artística disponible en este sentido: un modelo de investigación narrativa al alcance de cualquiera para indagar en las zonas más oscuras del pasado colectivo que conecta directamente con las urgencias del proceso de construcción de una memoria democrática. Y lo hace, precisamente, a través de la exhumación simbólica de historias a medio enterrar y de relatos confinados durante décadas en los cajones y veladores de las casas de nuestras abuelas. $Y$ también es tarea de la crítica el estar atentas a la aparición de esos nuevos relatos cuando surjan, para darles valor y aceptar su invitación a violentar el decoro memorial para establecer un diálogo conjunto que acompañe a la construcción del nuevo paradigma de la memoria democrática. 
NOTAS

CRÍTICAS

\section{En busca de}

textualidades críticas.

Ortodoxia memorial

y campo literario

Violeta Ros Ferrer

Universitat de València

DOI: 10.1344/452f.2021.25.15

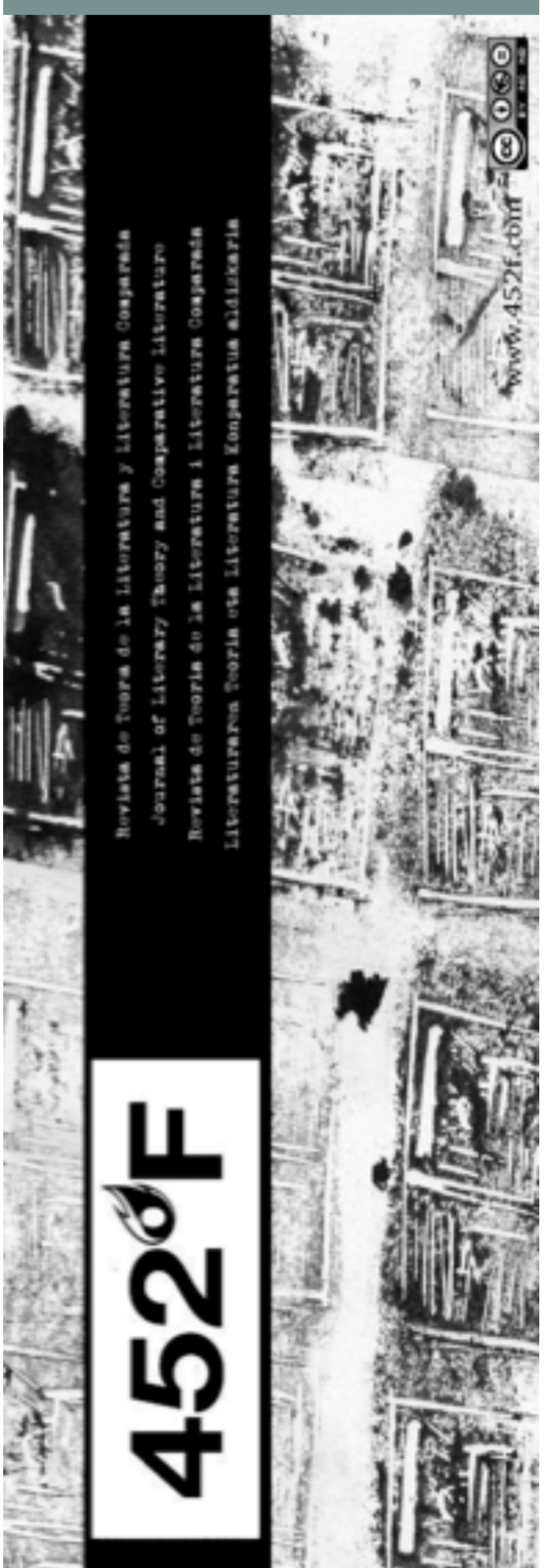

\section{Notas}

1 Esta fórmula se la escuché a Francisco Ferrándiz en una conversación a propósito de los espacios de memoria en el contexto de la nueva ley de memoria democrática. Esta conversación está publicada en forma de entrevista en el número monográfico de la revista Pasajes de pensamiento contemporáneo dedicado a las «Topografías del crimen», (Ros Ferrer, 2021).

\section{Bibliografía citada}

HALBWACHS, M. (2004): La memoria colectiva, Zaragoza: Prensas de la Universidad de Zaragoza.

LABRADOR, G. (2011): "Historia y decoro. Éticas de la forma en las narrativas de memoria histórica» en Contornos de la narrativa española actual (2000-2010). Un diálogo entre creadores y críticos, Madrid: Iberoamericana-Vervuert, 121-130.

LUENGO, A. (2017): «La última victoria del franquismo: el oikos como patria, el despot como padre», HIOL: Hispanic Issue On Line (Número dedicado a «Perpetradores y memoria democrática en España»), núm. 19, 26-43, < https://conservancy.umn.edu/bitstream/handle/11299/1922 20/hiol_19_02_luengo.pdf?sequence=1\&isAllowed=y>.

RENOV, $\bar{M}$. (2004): The subject of documentary, Minneapolis: University of Minnesota Press.

ROS FERRER, V. (2021): "Si pensamos en espacios de perpetración, no hay nada comparable al Valle de los Caídos. Conversación con Francisco Ferrándiz» (En el monográfico "Topografías del crimen y de la memoria»), Pasajes. Revista de pensamiento contemporáneo, núm. 62, 97-119.

WINTER, U. (2018): «Memoria histórica e imaginación jurídica: políticas estéticas de la memoria, desde la justicia poética al "forensic turn"», Memoria y narración. Revista de estudios sobre el pasado conflictivo de sociedades y culturas contemporáneas, num. 1, pp.184-197, <https://journals.uio.no/MyN/article/view/6012/5481>.

WELZER, H.; MOLLER, S. y TSCHUGGNALL, K. (2012): Mi abuelo no era nazi. El nacionalsocialismo y el Holocausto en la memoria familiar, Buenos Aires: Prometeo Libros. 